\title{
INFLUENCE OF MOISTURE ON THERMAL PROPERTIES OF WALLS IN BASEMENTS OF BUILDINGS
}

\author{
Pavel Kic \\ Czech University of Life Sciences Prague, Czech Republic \\ kic@tf.czu.cz
}

\begin{abstract}
This paper is focused on the problems of increased moisture in the structure of buildings, especially in basements of buildings, which have usually very poor insulation against ground moisture. Wet walls are rather a common problem of old buildings, but it can appear also in new buildings as well. Moisture in the wall influences the insulation quality; bigger heat losses continuously cause problems of worse heat balance, higher consumption of energy for heating and it can result in not sufficient indoor conditions in such a room or building. The aim of this paper is to present the results of evaluation of the main thermal-heat properties in basement rooms with partly wet and partly dry peripheral wall. The surface temperature and surface moisture were determined by measurement in wet and dry parts of the wall in the same room. The moisture of the wet part was approximately four times higher than of the dry part of the wall. The heat flux density passing from the heated room through the wall was also measured using a special sensor. The measurement results showed a significant effect of high wall moisture on the heat losses, as the heat flux density was one and a half times higher. The obtained results from this measurement and findings may be useful for further research in this issue as well as for practical solutions for similar problems in many older buildings.
\end{abstract}

Keywords: energy flux, humidity, measurement, temperature.

\section{Introduction}

Moisture of walls in the basement and ground floor of the building is a common problem of many old buildings. The use of basement as living or working space requires ensuring a comfortable indoor climate and prevention of condensation and mold formation [1].

Water penetrates into the walls in a liquid and gaseous state. Water moisture gets into the structure by diffusion of water vapor by capillary action of humidity and capillary condensation. These effects are reflected on the construction by dark and salt spots on the surface of a wall, a gradual sloughing of the walls and supporting structures disruption. Further, these phenomena manifest themselves by raising the humidity in rooms, thereby by worsening the use of space in terms of hygiene. Two years after reconstruction work, the microclimate in the basement of the Palace of Signatories has deteriorated [2]. Excess moisture has caused salt efflorescence, staining of the exterior walls and ceilings and spread of an unpleasant smell throughout the building. The tests showed that damp-proofing of the basement exterior walls was inadequate. Dampness has caused salt efflorescence on the facing of the basement walls and other building structures.

Water acting on the structure can be of atmospheric, subsurface or internal operation and use of the room origin. Atmospheric water is rainfall which runs down the structures or seeps into the soil near the building. Subsurface water is contained in a natural environment and is bound by sorption and capillary forces. By capillary action it penetrates into the structure at the missing or damaged surface waterproofing membrane.

Operating humidity is released from various sources of humidity indoors in the air such as mainly by people, plants, technical equipment in the bathroom, the kitchen and oven, or from technological equipment in the workshop etc. When the temperature of the walls falls below the dew point on the surface condensed water from vapor occurs, e.g., in corners, on parapets around the windows, in places of thermal bridges etc. Water can migrate through basement walls due to hydrostatic pressure, capillary action, and vapor pressure [3].

A new approach to moisture detection in buildings by an optical infrared thermography method is presented in several papers [4-7]. Infrared thermography was used to map moisture distribution and to identify areas with anomalous water content in modern and ancient building structures. Appropriate solutions of moisture reduction in the basements of the buildings need to be addressed individually, with respect to the dimensions and to the age of the building, with good knowledge of used building materials and their damage and especially with identification of the source of moisture in the building. The publication (7) contains a brief overview of some basic methods including solutions and 
achievements. The aim of this paper is to verify the methods for identification of moisture, including early identification of locations through which the moisture in the walls is spread.

The research problems of this paper are focused on the example of a subterranean basement room with high moisture on the walls. There are presented typical features and symptoms of high humidity, suitable and available methods of measurement, assessment and the method for identifying the sources of moisture in the wall. The main attention is paid to the measurement of heat flux through the moisture wall, which is compared with the dry wall of the same room. The main results published in this paper significantly indicate the influence of moisture in the walls on heat flux passing through the walls to surroundings.

\section{Materials and methods}

To verify the described principles of research and techniques of measurement an underground basement room with a total area approximately $110 \mathrm{~m}^{2}$ was chosen. The room is used mainly for storage and occasionally for laboratory experiments. The reasons of wall moisture are poorly made outdoor vertical insulations and capillary rising water.

Air temperatures and relative humidity were measured by the sensor FHA 646-21 including the temperature sensor NTC type $\mathrm{N}$ with operative range from -30 to $+100{ }^{\circ} \mathrm{C}$ with accuracy $\pm 0.1{ }^{\circ} \mathrm{C}$, and air humidity by the capacitive sensor with operative range from 5 to $98 \%$ with accuracy $\pm 2 \%$ connected to the measuring instrument ALMEMO 2590-9 (Ahlborn GmbH, Germany) placed in the center of the room, $80 \mathrm{~cm}$ above the floor.

Capacitive sensor FH A696-MF with operative range of mineral construction materials from 0 to $20 \%$ with accuracy $0.1 \%$ was used for the indirect measurement of wall moisture. The sensor was connected to the data logger ALMEMO 2690-8 (Ahlborn GmbH, Germany).

The surface temperatures of the walls were measured by the thermographic camera IR Flexcam Pro (Infrared Solutions INC, USA) with operative range from -30 to $+350{ }^{\circ} \mathrm{C}$ with accuracy $\pm 2{ }^{\circ} \mathrm{C}$. Instantaneous values of surface temperatures (thermograms) were stored in the device memory and then analyzed in a PC using special software Infrared Solutions FlexView 1.2.2 designed for this thermographic camera. This application was very useful especially for processing of thermograms, which were statistically evaluated.

The surface temperatures in some specific places of the tested walls were measured by infrared measurement infrared pyrometer AMIR 7811 (Ahlborn GmbH, Germany) for non-contact temperature measurement. This instrument can be used in operative range from -32 to $+400{ }^{\circ} \mathrm{C}$, with display resolution $0.2{ }^{\circ} \mathrm{C}$ and with accuracy $\pm 1 \%$ from the measured value.

The heat flux density were measured by a special heat flux sensor FQA018C (Ahlborn GmbH, Germany), which has dimensions $120 \cdot 120 \cdot 1.5 \mathrm{~mm}$. It is made from epoxy resin with the resistance to $80^{\circ} \mathrm{C}$ and calibration constant $9.69 \mathrm{~W} \cdot \mathrm{m}^{-2} \cdot \mathrm{mV}^{-1}$ and relative measurement uncertainty $5 \%$.

The results of the measurement were processed by Excel software and verified by statistical software Statistica $12 \mathrm{~s}$

\section{Results and discussion}

The results of the measurements are summarized and presented in Figs. 1-4 and Table 1.

Photos of the surface of dry and wet parts of the wall are in Fig. 1. High moisture of some parts of the wall is also demonstrated at lower temperatures of these walls. The difference of temperatures in various parts of inner surfaces of the peripheral wall is visible on the thermograms, Fig. 2.

The mean values and standard deviations (SD) calculated from the results of measurements of the air temperature $t_{a}$ and relative humidity $R h_{a}$, surface temperature $t_{S W}$ and moisture $R h_{S W}$ of the wall and heat flux density $q$ measured on the dry and wet parts of the wall are summarized in Table 1, where $S D$ is standard deviation and different letters $(\mathrm{a}, \mathrm{b})$ in the superscript are the sign of high significant difference (ANOVA; Tukey HSD Test; $p \leq 0.05$ ). 

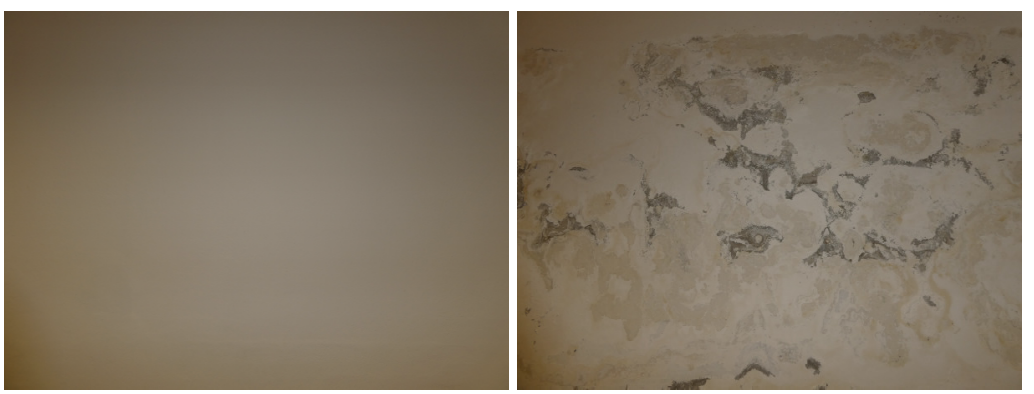

Fig. 1. Photos of the dry (left) and wet (right) parts of the wall
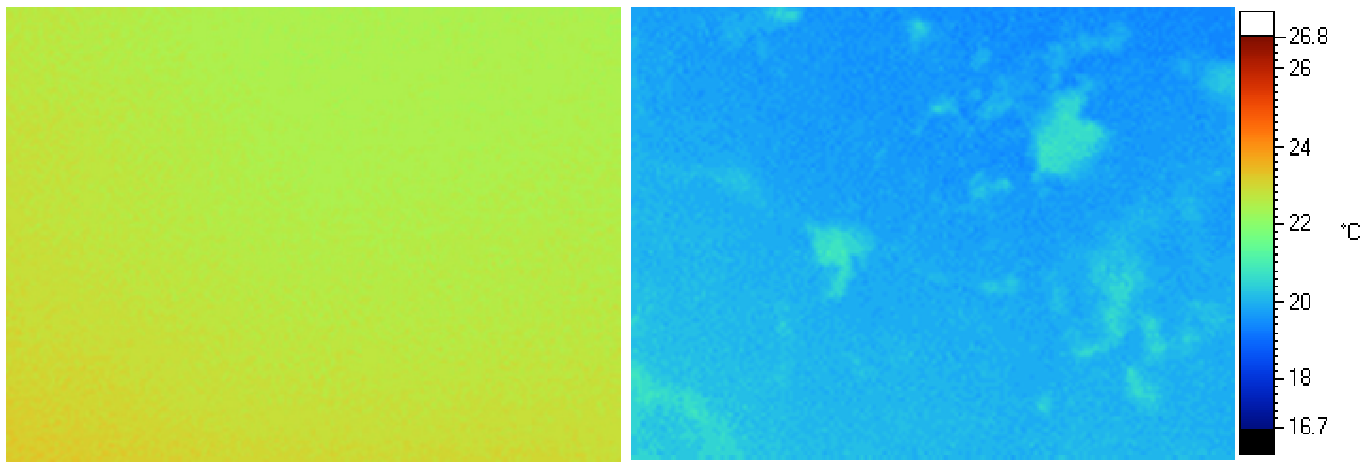

Fig. 2. Thermograms of the dry (left) and wet (right) parts of the wall

The air temperature $t_{a}$ and relative humidity $R h_{a}$ measured in the center of the room were influenced by the total heat balance of the room. The higher moisture $R h_{S W}$ of the wet part of the wall influenced the thermal properties of this part of the wall very negatively. It resulted in lower surface temperature $t_{S W}$ as well as worse thermal insulation of the wall and extremely higher heat flux density $q$ into the wet wall in comparison with the dry parts of the wall. The differences between the measured values on the dry and wet parts of wall are statistically significant.

Results of measurement of the air and on the dry and wet parts of the wall

Table 1

\begin{tabular}{|c|c|c|c|c|c|}
\hline Wall & $\boldsymbol{t}_{\boldsymbol{a}},{ }^{\mathbf{}} \mathbf{C}$ & $\boldsymbol{R h}_{\boldsymbol{a}}, \boldsymbol{\%}$ & $\boldsymbol{t}_{\boldsymbol{S W}},{ }^{\mathbf{}} \mathbf{C}^{\mathrm{a}}$ & $\boldsymbol{R} \boldsymbol{h}_{\boldsymbol{S W}}, \boldsymbol{\%}$ & $\boldsymbol{q}, \mathbf{W} \cdot \mathbf{m}^{-2}$ \\
\hline Dry part & $21.9 \pm 0^{\mathrm{a}}$ & $39.6 \pm 0^{\mathrm{a}}$ & $22.69 \pm 0.07^{\mathrm{a}}$ & $5.95 \pm 0.27^{\mathrm{a}}$ & $55.23 \pm 7.5^{\mathrm{a}}$ \\
\hline Wet part & $21.9 \pm 0^{\mathrm{a}}$ & $39.6 \pm 0^{\mathrm{a}}$ & $19.99 \pm 0.07^{\mathrm{b}}$ & $24.58 \pm 3.72^{\mathrm{b}}$ & $84.07 \pm 12.51^{\mathrm{b}}$ \\
\hline
\end{tabular}

The surface temperature $t_{S W}$ and heat flux density $q$ as a function of the wall moisture $R h_{S W}$, is presented in Figs. 3 and 4. The linear regression used in Fig. 3 and 4 indicates for investigated conditions of the wall humidity the effect of moisture on a decrease of the wall surface temperature and a significant increase of the heat flux density.

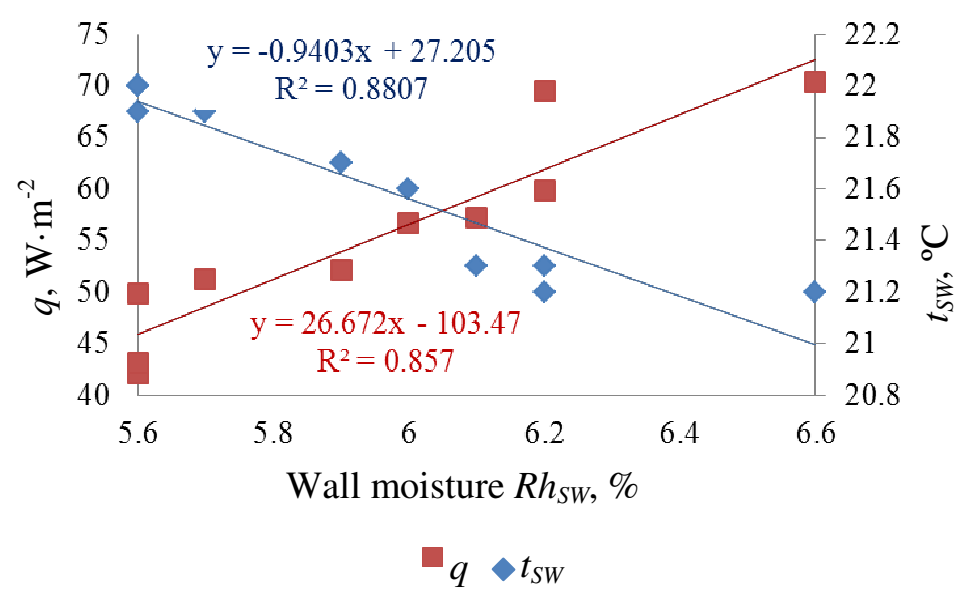

Fig. 3. Surface temperature $t_{S W}$ and heat flux density $q$ as a function of the wall moisture $R h_{S W}$ in dry parts of the wall 


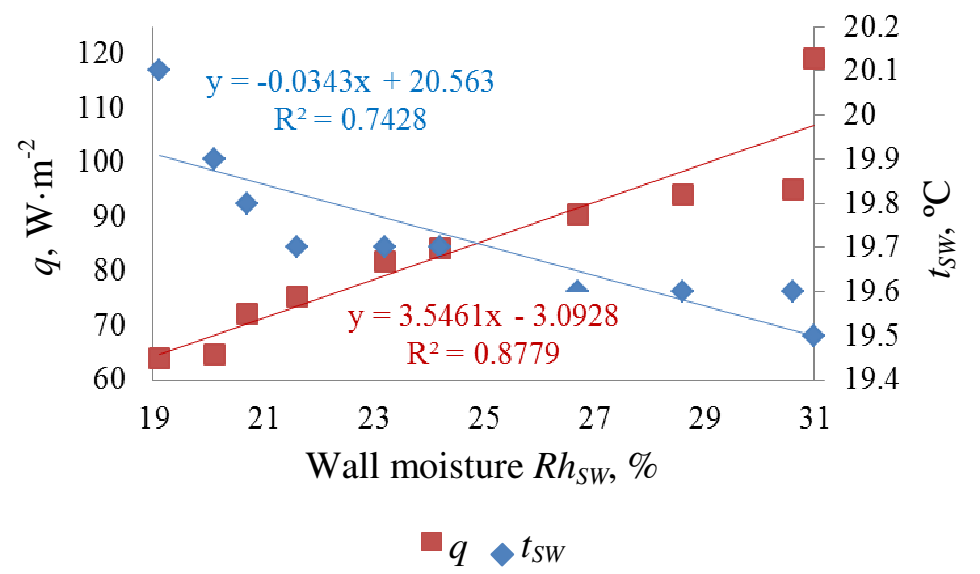

Fig. 4. Surface temperature $t_{S W}$ and heat flux density $q$ as a function of the wall moisture $R h_{S W}$ in wet parts of the wall

\section{Conclusions}

1. The measurement results showed that it is suitable by measuring the temperature and moisture to identify the place and sources of problems causing high air humidity and moisture in the walls.

2. The results of measurement of surface temperatures and moisture in different locations of the wall showed the dependence of the surface temperature on the wall moisture.

3. The surface measurements by pyrometers or infrared thermography are useful methods for detection of moisture changes in the parts of walls, which cannot be identified visually.

4. Increasing humidity of walls and decreasing the surface temperature reduces thermal insulation and grows heat flux passing through the walls to surroundings.

\section{References}

1. Rucker-Gramm P. Bauphysikalische Aspekte bei Ausführung von hochwertig genutzen Weissen Wannen (Aspects of building physics in the course of constructing high grade white tanks). Beton- und Stahlbetonbau, vol. 109, 2014, pp. 65-80. (In German).

2. Ignatavicius C., Ignatavicius G. Investigation of damage and microclimate deterioration caused by dampness in the palace of signatories to the declaration of independence. Indoor and Built Environment, vol. 14 (1), 2005, pp. 89-95.

3. Day R.W. Moisture migration through basement walls. Journal of Performance of Constructed Facilities, vol. 8 (1), 1994, pp. 82-86.

4. Grinzato E., Cadelano G., Bison P. Moisture map by IR thermography. Journal of Modern Optics, vol. 57 (18), 2010, pp. 1770-1778.

5. Barreira E., Almeida R.M.S.F., Delgado J.M.P.Q. Infrared thermography for assessing moisture related phenomena in building components. Construction and building materials, vol. 110, 2016, pp. 251-269.

6. Grinzato E., Ludwig N., Cadelano G., Bertucci M., Gargano M., Bison P. Infrared thermography for moisture detection: A laboratory study and in-situ test. Materials Evaluation, vol. 69 (1), 2011, pp. 97-104.

7. Prejza M., Kic P. Reduction of moisture in basements of buildings. Proceedings of International Scientific Conference "Engineering for Rural Development". 2016, Jelgava, Latvia University of Agriculture, Latvia, pp. 68-73. 